\title{
Impact of Tumor Grade on Prognosis in Pancreatic Cancer: Should We Include Grade in AJCC Staging?
}

\author{
Nabil Wasif, MD ${ }^{1}$, Clifford Y. Ko, MD, MSHS ${ }^{2,3}$, James Farrell, $\mathrm{MD}^{4}$, Zev Wainberg, $\mathrm{MD}^{5}$, Oscar J. Hines, $\mathrm{MD}^{2}$, \\ Howard Reber, $\mathrm{MD}^{2}$, and James $\mathrm{S}$. Tomlinson, $\mathrm{MD}, \mathrm{PhD}^{2,3}$ \\ ${ }^{1}$ John Wayne Cancer Institute at Saint John's Health Center, Santa Monica, CA; ${ }^{2}$ Department of Surgery, David Geffen \\ School of Medicine at UCLA, Los Angeles, CA; ${ }^{3}$ Department of Surgery, Greater Los Angeles VA Healthcare System, Los \\ Angeles, CA; ${ }^{4}$ Division of Digestive Diseases, David Geffen School of Medicine at UCLA, Los Angeles, CA; ${ }^{5}$ Division of \\ Hematology, David Geffen School of Medicine at UCLA, Los Angeles, CA
}

\begin{abstract}
Background. AJCC staging of pancreatic cancer (PAC) is used to determine prognosis, yet survival within each stage shows wide variation and remains unpredictable. We hypothesized that tumor grade might be responsible for some of this variation and that the addition of grade to current AJCC staging would provide improved prognostication.

Methods. The Surveillance, Epidemiology, and End Results (SEER) database (1991-2005) was used to identify 8082 patients with resected PAC. The impact of grade on overall and stage-specific survival was assessed using Cox regression analysis. Variables in the model were age, sex, tumor size, lymph node status, and tumor grade.
\end{abstract}

Results. For each AJCC stage, survival was significantly worse for high-grade versus low-grade tumors. On multivariate analysis, high tumor grade was an independent predictor of survival for the entire cohort (hazard ratio [HR] $1.40,95 \%$ confidence interval [95\% CI] 1.31-1.48) as well as for stage I (HR 1.28, 95\% CI 1.07-1.54), stage IIA (HR 1.43, 95\% CI 1.26-1.61), stage IIB (HR 1.38, 95\% CI 1.27-1.50), stage III (HR 1.28, 95\% CI 1.02-1.59), and stage IV (HR 1.58, 95\% CI 1.21-2.05) patients. The addition of grade to staging results in a statistically significant survival discrimination between all stages.

Conclusions. Tumor grade is an important prognostic variable of survival in PAC. We propose a novel staging

No financial disclosures or conflicts of interest for any of the authors.

(C) The Author(s) 2010. This article is published with open access at Springerlink.com

First Received: 19 April 2009;

Published Online: 27 April 2010

J. S. Tomlinson, $\mathrm{MD}, \mathrm{PhD}$

e-mail: james.tomlinson@va.gov system incorporating grade into current AJCC staging for pancreas cancer. The improved prognostication is more reflective of tumor biology and may impact therapy decisions and stratification of future clinical trials.

The American Joint Commission on Cancer (AJCC) tumor node metastasis (TNM) staging system is the "language of cancer" by which physicians communicate about the disease process. ${ }^{1}$ Staging ensures an objective, reproducible classification of the extent of disease and is our most important determinant of treatment recommendations. For research purposes, clinical trials depend on staging for appropriate patient stratification upon which accurate measurement of the treatment effect under study can be performed. Perhaps most importantly to the patient, staging is our best tool to provide prognostic information in our effort to manage patient expectations in the context of a suggested treatment plan.

Current staging for pancreatic cancer is based on the 6th edition of the AJCC Cancer Staging Manual, published in 2002 (Table 1). ${ }^{2}$ This update has been validated for pancreatic cancer using the National Cancer Database (NCDB) and shown to have good survival discrimination between stages. ${ }^{3}$ However, because survival within a particular stage is highly variable, the Memorial Sloan Kettering Cancer Center (MSKCC) developed a nomogram to better predict the likelihood of disease-specific survival after initial resection for pancreatic carcinoma. ${ }^{4}$ This nomogram incorporates additional factors into the predictive model not included in traditional TNM staging, one of which is the degree of differentiation or grade of the tumor. Predictions by the nomogram discriminated better than AJCC stage, suggesting that incorporation of additional variables 
TABLE 1 American Joint Committee on Cancer (AJCC) 6th edition TNM staging system for pancreatic cancer

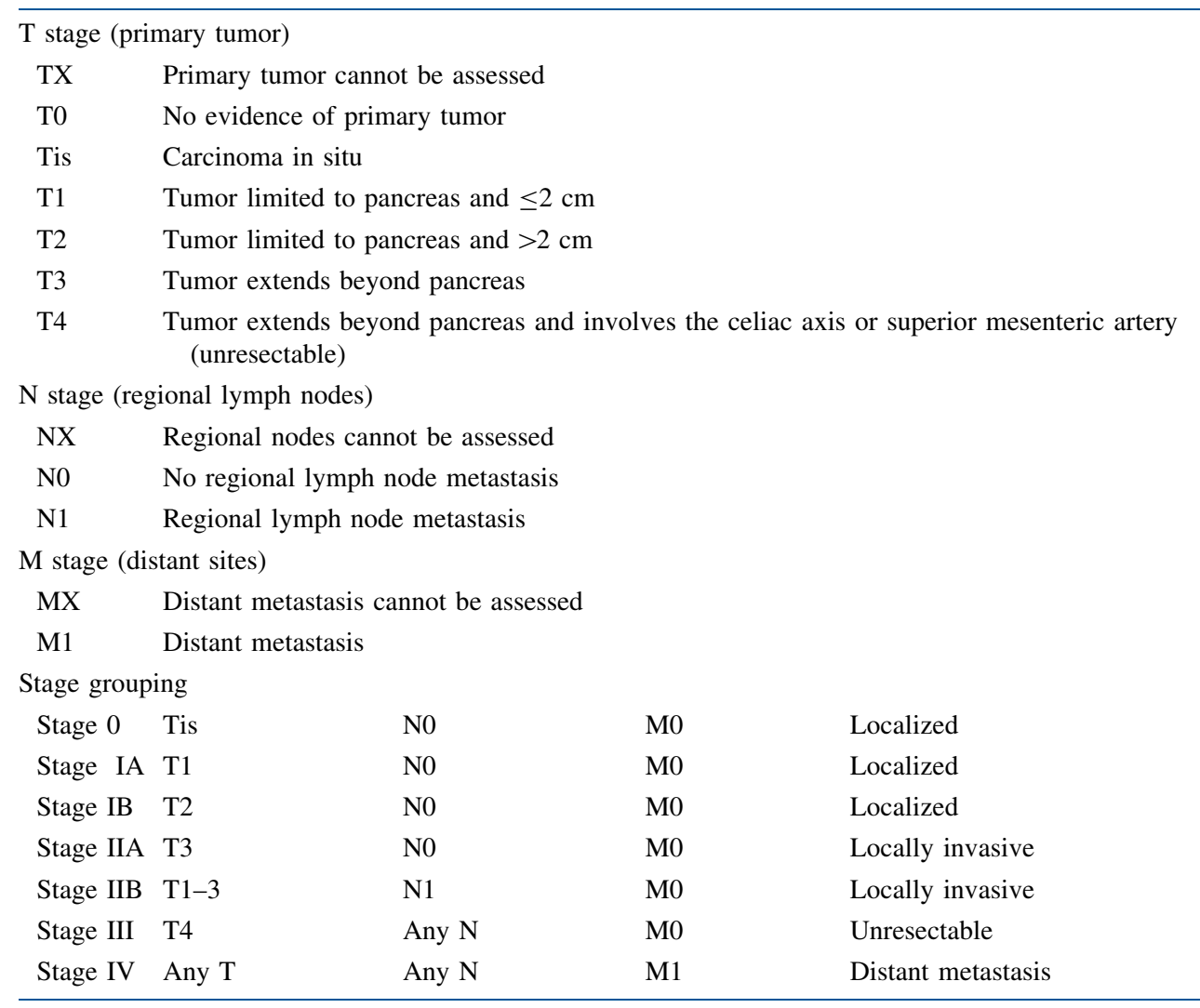

would improve accuracy. This nomogram was independently validated by the group at Massachusetts General Hospital on a cohort of 424 patients. $^{5}$

Several other multivariate analyses have shown that tumor grade is an important prognostic indicator after resection of pancreatic cancer. ${ }^{6-11}$ Grade is a measure of the degree of differentiation of the tumor. Differentiation refers to the morphologic and functional resemblance between a tumor cell and a normal cell of the same tissue. Malignant neoplasms range from well differentiated (low grade) to undifferentiated (high grade); in general, the more undifferentiated the tumor, the more aggressive the malignant biology. ${ }^{12}$ For pancreatic adenocarcinomas, histologic grade is based on the extent of glandular differentiation. If $>95 \%$ of the tumor is composed of glands then it is classified as being well differentiated, $50 \%-95 \%$ is moderately differentiated, and $<50 \%$ is poorly differentiated. ${ }^{2}$

The aim of this study was to use a population-based database providing significant power to assess the impact of tumor grade on prognosis after resection for pancreatic cancer. We hypothesized that some of the variability in survival within the same AJCC stage might be the result of differences in tumor grade. Our goal was to assess the significance of tumor grade as a predictive factor independent of known adverse predictors of survival. Furthermore, we sought to develop a novel staging system that would incorporate grade into the existing TMN system in hopes of providing improved staging that is more reflective of the underlying tumor biology and associated survival.

\section{METHODS}

\section{SEER Database}

The National Cancer Institute's Surveillance, Epidemiology, and End Results (SEER) tumor registry database was used for this study. SEER contains more than 3 million cases from 17 geographic sites, covering approximately $26 \%$ of the U.S. population. The database was designed to reflect the overall characteristics of the U.S. population and is regarded as a model population-based tumor registry. Quality control is an important component of the SEER program; the current standard for accuracy of the data in the registry is an error rate of less than 5\%. ${ }^{13}$ SEER Program registries routinely collect data on patient demographics (e.g., age, sex), primary tumor characteristics (e.g., size, extent, grade), nodal staging (number of nodes examined, number of positive nodes), surgery performed (pancreaticoduodenectomy vs distal pancreatectomy), vital status, and survival. Although information on radiation therapy is recorded, no information on chemotherapy is reported. The November 2007 update was used for this study, providing 
information from 1973 to $2005 .{ }^{14}$ As a population-based study with no patient identifiers involved, our study was exempt from institutional research board review.

\section{Case Selection}

The study period was from 1991 to 2005 . The ICD-10 histology codes $8000,8010,8020,8021,8140,8141$, and 8500 were used to identify all patients with a diagnosis of adenocarcinoma of the pancreas. Patients who did not undergo cancer-directed surgery were excluded from the analysis. Also excluded were patients with no histological confirmation of the diagnosis and cases identified from autopsy reports only. Although no specific field for AJCC stage in pancreatic cancer is provided in the SEER database, the information to accurately stage patients is present in other data fields. Using extent of disease (EOD) data fields, we were able to determine stage according to the 6th edition of the AJCC Staging Manual, as our group and others have done so previously. ${ }^{15,16}$ Complete TNM data were available for 7627 out of 8082 patients (94.4\%) using the EOD codes. In the SEER database, tumor grade is coded as 1 (well differentiated), 2 (moderately differentiated), 3 (poorly differentiated), or 4 (undifferentiated). Tumor grade was recorded for 7086 out of 8082 patients $(88 \%)$.

\section{Statistical Analysis}

Kaplan-Meier curves and log-rank tests were used to identify differences in overall survival, defined as duration of survival after initial resection of pancreatic carcinoma. Predictors of survival after surgical resection for the entire cohort were identified by Cox regression analysis using proportional hazards modeling. Variables included in the model were age, sex, tumor size, lymph node status, and tumor grade. Only patients with complete data were included in the multivariate analysis. Thus, 5935 of 8082 patients were eligible for inclusion in the multivariate analysis. A separate multivariate analysis was performed to identify predictors of survival for stages I, IIA, IIB, III, and IV individually. Stages IA and IB were combined together to ensure adequate numbers for analysis. For stages I, IIA, and IIB variables in the model were age, sex, tumor size, and tumor grade only. Lymph node status was not included because by definition all patients in stages I and IIA are node negative and patients in stage IIB are node positive. In our study, grade was redefined as a dichotomous, categorical variable: tumor grades 1 (well differentiated) and 2 (moderately differentiated) were combined into a "lowgrade" group and tumor grades 3 (poorly differentiated) and 4 (undifferentiated) into a "high-grade" group. Categorical variables were compared between low-grade and high-grade groups using chi-square analysis. Differences between continuous variables were determined using $t$ test. Significance levels were set at $P<.05$ and confidence intervals were $95 \%$. All tests were two-tailed. Predictors of high tumor grade were identified using logistic regression analysis. Factors included in the model were sex, tumor size, lymph node status, and presence of extrapancreatic invasion. Patients with incomplete data were excluded from regression analysis. All statistical analysis was performed using SPSS 16.0 statistical software (SPSS Inc., Chicago IL).

\section{RESULTS}

Our study population consisted of 8082 patients who underwent resection of pancreatic adenocarcinoma. Demographic, tumor, and treatment characteristics of the entire cohort as well as low-grade and high-grade groups are detailed in Table 2. A total of $996(12 \%)$ patients did not have tumor grade recorded. Significant differences were seen between the high-grade and low-grade cohort with regard to sex, tumor size, lymph node involvement, number of positive nodes, AJCC stage, and reception of radiation treatment.

For each AJCC stage classification, survival was significantly worse with high-grade ( 3 or 4 ) versus low-grade (1 or 2 ) tumors (Fig. 1). Multivariate analysis of the entire cohort identified the following independent predictors of adverse outcome: increasing age, male sex, tumor size $>2 \mathrm{~cm}$, lymph node positivity, and high tumor grade. Importantly, the hazard ratio (HR) associated with high tumor grade $(\mathrm{HR}=1.4)$ was of a similar magnitude and significance when compared with tumor size $(\mathrm{HR}=1.37)$ and node status $(\mathrm{HR}=1.38)$. When each stage was analyzed separately, high tumor grade remained an independent predictor of survival across all stages (Table 3). Interestingly, in the stage IV patients who underwent a resection, grade was the only independent prognostic variable $(\mathrm{HR}=1.58)$.

Predictors of high tumor grade were tumor size $>2 \mathrm{~cm}$ (odds ratio [OR] 1.39, 95\% confidence interval [95\% CI] $1.18-1.65, P<.001$ ), positive lymph nodes (OR $1.24,95 \%$ CI $1.08-1.42, P=.002$ ), and peripancreatic invasion (OR $1.20,95 \%$ CI $1.03-1.41, P=.02)$. Female sex was a protective factor (OR .85, 95\% CI .74-.97, $P=.013$ ).

Tumor grade (G) was incorporated into AJCC (TNM) staging system to generate a novel TNMG staging system for 6862 out of 8082 patients (84.9\%). This TNMG staging differs from the AJCC staging by advancing a patient to the next higher stage level in the presence of high tumor grade (Table 4). For instance a high-grade stage IIA tumor in the TNM staging system would now be a stage IIB tumor in 
TABLE 2 Demographic, tumor and treatment characteristics

\begin{tabular}{|c|c|c|c|c|}
\hline Demographics & $\begin{array}{l}\text { All patients } \\
(n=8082)\end{array}$ & $\begin{array}{l}\text { Low-grade tumor }{ }^{\mathrm{a}} \\
(n=4491)\end{array}$ & $\begin{array}{l}\text { High-grade tumor } \\
(n=2595)\end{array}$ & $P$ value \\
\hline $\operatorname{Sex}(\%)$ & & & & .009 \\
\hline Male & 50.4 & 49.0 & 52.3 & \\
\hline Age (y) & & & & NS \\
\hline Mean \pm SD & $65.2 \pm 11.0$ & $65.2 \pm 10.8$ & $65.3 \pm 10.9$ & \\
\hline Median & 66.0 & 66.3 & 66.5 & \\
\hline Race $(\%)$ & & & & NS \\
\hline White & 83.1 & 82.9 & 84.2 & \\
\hline Black & 9.9 & 9.9 & 9.2 & \\
\hline Other & 6.8 & 7.3 & 6.6 & \\
\hline Tumor location (\%) & & & & NS \\
\hline Head & 85.6 & 85.7 & 85.4 & \\
\hline Body & 5.1 & 5.2 & 4.9 & \\
\hline Tail & 9.4 & 9.1 & 9.7 & \\
\hline Type of surgery (\%) & & & & NS \\
\hline Whipple procedure & 82.4 & 82.2 & 82.7 & \\
\hline Distal pancreatectomy & 9.3 & 9.4 & 9.2 & \\
\hline Total pancreatectomy & 8.3 & 8.4 & 8.0 & \\
\hline Tumor size $(\mathrm{cm})$ & & & & $<.001$ \\
\hline Mean \pm SD & $3.5 \pm 1.9$ & $3.4 \pm 1.8$ & $3.7 \pm 2.1$ & \\
\hline Median & 3.1 & 3.0 & 3.4 & \\
\hline Lymph node status (\%) & & & & $<.001$ \\
\hline Positive & 60.3 & 57.9 & 64.6 & \\
\hline AJCC state $(\%)$ & & & & $<.001$ \\
\hline IA & 4.3 & 5.2 & 2.7 & \\
\hline IB & 8.1 & 8.7 & 7 & \\
\hline IIA & 24.6 & 25.7 & 22.7 & \\
\hline IIB & 49.5 & 48.6 & 51 & \\
\hline III & 6.8 & 6.5 & 7.4 & \\
\hline IV & 6.7 & 5.2 & 9.1 & \\
\hline Number of nodes examined & & & & NS \\
\hline Mean \pm SD & $9.8 \pm 8.0$ & $9.8 \pm 8.0$ & $9.8 \pm 8.0$ & \\
\hline Median & 8.0 & 8.0 & 8.0 & \\
\hline Number of positive nodes & & & & .006 \\
\hline Mean $\pm \mathrm{SD}$ & $2.9 \pm 2.6$ & $2.9 \pm 2.5$ & $3.1 \pm 2.7$ & \\
\hline Median & 2.1 & 2.0 & 2.6 & \\
\hline Radiation (\%) & & & & .001 \\
\hline Yes & 42.7 & 44.2 & 40.2 & \\
\hline
\end{tabular}

the novel TNMG system. By restaging patients in this manner, the impact of grade on survival can be realized, as demonstrated by a 2-month improvement in median survival of stage IIA patients simply by advancing patients with high-grade tumors and associated worse survival into stage IIB. Excellent discrimination in overall survival between stages is also seen in this novel TNMG staging classification and appears to be durable throughout all time points as the curves remain separate through 5 years (Fig. 2).

\section{DISCUSSION}

The aim of this study was to use a population-based tumor registry to assess the impact of tumor grade on prognosis after surgical resection for pancreatic cancer. We believe that the variability in survival within each AJCC stage may be attributed to factors not currently incorporated into the staging system, one of which is tumor grade. Our data show that within each AJCC stage, high tumor grade is an independent and significant predictor of adverse 

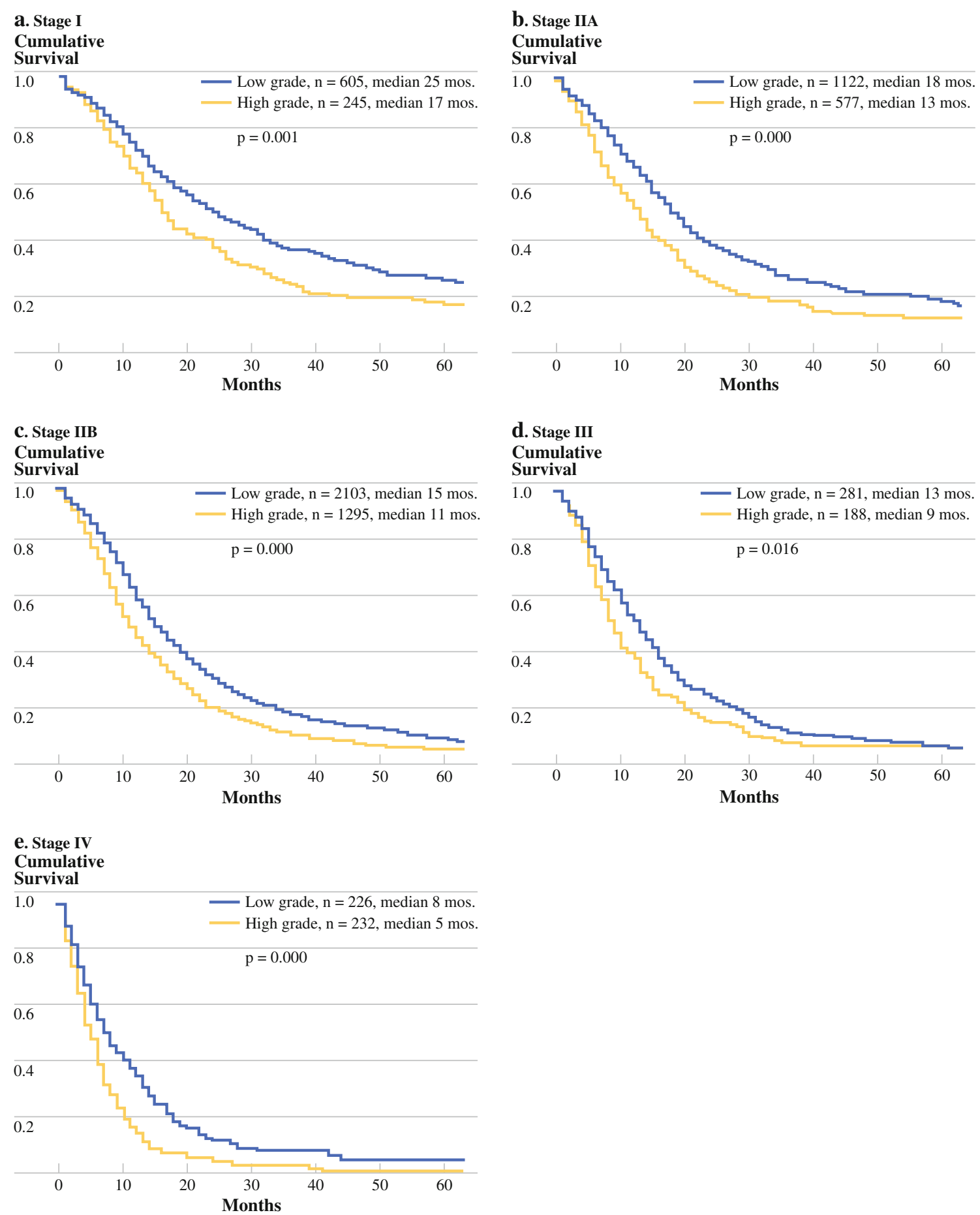

FIG. 1 Kaplan-Meier survival curves stratified by grade for patients with stage I (a), stage IIA (b), stage IIB (c), stage III (d), and stage IV (e) disease

outcome. When patients are restaged with grade incorporated into a novel TNMG staging system, excellent discrimination in survival between stages is seen.

The largest series on surgical resection for pancreatic cancer in the literature includes 1423 patients who underwent pancreaticoduodenectomies at the Johns Hopkins
Medical Institutions. ${ }^{8}$ Among other variables, the authors report histologic grade as an independent predictor of survival on multivariate analysis, with a hazard ratio of 1.6. Other single-institution studies have confirmed this on both univariate and multivariate analysis with a hazard ratio that varies between 1.14 and $2.56 .^{9-11}$ Our population-based 
TABLE 3 Cox regression analyses

\begin{tabular}{|c|c|c|}
\hline Patient group & Hazard ratio $(95 \% \mathrm{CI})$ & $P$ value \\
\hline \multicolumn{3}{|c|}{ Entire cohort $(n=5935)$} \\
\hline \multicolumn{3}{|l|}{ Age (y) } \\
\hline$<55^{\mathrm{a}}$ & 1.00 & \\
\hline $56-65$ & $1.10(1.01-1.21)$ & .037 \\
\hline $66-75$ & $1.26(1.16-1.37)$ & $<.001$ \\
\hline$>75$ & $1.48(1.35-1.64)$ & $<.001$ \\
\hline \multicolumn{3}{|l|}{ Sex } \\
\hline Female $^{\mathrm{a}}$ & 1.00 & \\
\hline Male & $1.07(1.00-1.13)$ & .035 \\
\hline \multicolumn{3}{|l|}{ Node status } \\
\hline Negative $^{\mathrm{a}}$ & 1.00 & \\
\hline Positive & $1.38(1.30-1.47)$ & $<.001$ \\
\hline \multicolumn{3}{|c|}{ Tumor size $(\mathrm{cm})$} \\
\hline$<2^{\mathrm{a}}$ & 1.00 & \\
\hline$>2$ & $1.37(1.27-1.48)$ & $<.001$ \\
\hline \multicolumn{3}{|c|}{ Tumor grade } \\
\hline Low $^{\mathrm{a}}$ & 1.00 & \\
\hline High & $1.40(1.31-1.48)$ & $<.001$ \\
\hline \multicolumn{3}{|c|}{ Stage I $(n=845)$} \\
\hline \multicolumn{3}{|l|}{ Age (y) } \\
\hline$<55^{\mathrm{a}}$ & 1.00 & \\
\hline $56-65$ & $1.21(.92-1.58)$ & .18 \\
\hline $66-75$ & $1.50(1.17-1.91)$ & .001 \\
\hline$>75$ & $1.72(1.31-2.26)$ & $<.001$ \\
\hline \multicolumn{3}{|c|}{ Tumor size $(\mathrm{cm})$} \\
\hline$<2^{\mathrm{a}}$ & 1.00 & \\
\hline$>2$ & $1.33(1.11-1.60)$ & .002 \\
\hline \multicolumn{3}{|c|}{ Tumor grade } \\
\hline Low $^{\mathrm{a}}$ & 1.00 & \\
\hline High & $1.28(1.07-1.54)$ & .007 \\
\hline \multicolumn{3}{|c|}{ Stage IIA $(n=1501)$} \\
\hline \multicolumn{3}{|c|}{ Tumor size $(\mathrm{cm})$} \\
\hline$<2^{\mathrm{a}}$ & 1.00 & \\
\hline$>2$ & $1.27(1.10-1.47)$ & .001 \\
\hline \multicolumn{3}{|l|}{ Tumor grade } \\
\hline Low $^{\mathrm{a}}$ & 1.00 & \\
\hline High & $1.43(1.26-1.61)$ & $<.001$ \\
\hline \multicolumn{3}{|c|}{ Stage IIB $(n=3140)$} \\
\hline \multicolumn{3}{|c|}{ Age (y) } \\
\hline$<55^{\mathrm{a}}$ & 1.00 & \\
\hline $56-65$ & $1.04(.92-1.17)$ & .543 \\
\hline $66-75$ & $1.23(1.10-1.38)$ & $<.001$ \\
\hline$>75$ & $1.54(1.34-1.76)$ & $<.001$ \\
\hline \multicolumn{3}{|c|}{ Tumor size $(\mathrm{cm})$} \\
\hline$<2^{\mathrm{a}}$ & 1.00 & \\
\hline$>2$ & $1.37(1.23-1.54)$ & $<.001$ \\
\hline \multicolumn{3}{|l|}{ Tumor grade } \\
\hline Low $^{\mathrm{a}}$ & 1.00 & \\
\hline High & $1.38(1.27-1.50)$ & $<.001$ \\
\hline
\end{tabular}

TABLE 3 continued

\begin{tabular}{lll}
\hline Patient group & Hazard ratio $(95 \% \mathrm{CI})$ & $P$ value \\
\hline $\begin{array}{l}\text { Stage III }(\boldsymbol{n}=\mathbf{3 8 4}) \\
\quad \text { Age }(\mathrm{y})\end{array}$ & \\
$\quad<55^{\mathrm{a}}$ & 1.00 & .29 \\
$56-65$ & $1.19(.86-1.64)$ & .047 \\
$\quad 66-75$ & $1.37(1.00-1.86)$ & .001 \\
$>75$ & $1.81(1.28-2.57)$ & \\
Tumor grade & & .032 \\
$\quad$ Low & \\
$\quad$ High & 1.00 & \\
Stage IV $(\boldsymbol{n}=\mathbf{2 7 0})$ & $1.28(1.02-1.59)$ & .001 \\
$\quad$ Tumor grade & & \\
$\quad$ Low & \\
$\quad$ High & 1.00 & \\
\hline$n=$ patients with all variables available for regression analysis & \\
a &
\end{tabular}

study reports a hazard ratio of 1.40 for high tumor grade, which falls well within the range reported in the literature.

Largely in concert with published studies, we found tumor size $>2 \mathrm{~cm}$, lymph node positivity, age, and male sex as adverse prognostic factors for the entire cohort. Tumor size and lymph node involvement are well-known prognostic indicators for pancreatic cancer and, along with distant metastases, form the trifecta of the current TNMbased AJCC staging for pancreatic cancer. Many studies have shown that patients with a tumor larger than $2 \mathrm{~cm}$ or lymph node involvement have a significantly lower median and 5-year survival. ${ }^{6-11,17-21}$ Other studies show that patients who are elderly have a worse outcome than younger patients after surgical resection of pancreatic cancer. $^{22,23}$ Similarly, we also show that males have poorer survival than females, which may be related to the presence of lower-grade tumors in females as demonstrated by our data. $^{4,5}$

Especially pertinent to the context of our study are clinical trials for adjuvant treatment of pancreatic cancer. In the CONKO-001 trial of adjuvant gemcitabine versus observation after resection of pancreatic cancer, the median overall survival was 22.8 months in the gemcitabine group and 20.2 months in the observation group $(P=.005) .^{24}$ Similarly in the ESPAC-1 trial, adjuvant chemotherapy with 5-fluorouracil/leucovorin had a statistically significant benefit over observation with respect to median survival (20.1 vs 15.5 months, $P=.009) .^{25}$ Lastly, the RTOG $97-$ 04 trial randomized patients to chemoradiotherapy using $5 F U$ versus chemoradiotherapy with gemcitabine. The results demonstrated a 3.7-month difference in median survival in favor of the chemoradiotherapy/gemcitabine 
TABLE 4 Restaging according to TNMG classification

\begin{tabular}{|c|c|c|c|c|}
\hline $\begin{array}{l}\text { TNM } \\
\text { Stage }\end{array}$ & $\begin{array}{l}\text { Median survival } \\
\text { (months) }\end{array}$ & $\begin{array}{l}\text { Tumor } \\
\text { Grade }\end{array}$ & $\begin{array}{l}\text { TNMG } \\
\text { Stage }\end{array}$ & $\begin{array}{c}\text { Median survival } \\
\quad \text { (months) }\end{array}$ \\
\hline \multirow[t]{2}{*}{ IA } & 27 & Low & IA & 30 \\
\hline & & High & & \\
\hline \multirow[t]{2}{*}{ IB } & 21 & Low & IB & 21 \\
\hline & & High & & \\
\hline \multirow[t]{2}{*}{ IIA } & 16 & Low & IIA & 18 \\
\hline & & High & & \\
\hline \multirow[t]{2}{*}{ IIB } & 14 & Low & IIB & 14 \\
\hline & & High & & \\
\hline \multirow[t]{2}{*}{ III } & 11 & Low & III & 11 \\
\hline & & High & & \\
\hline \multirow[t]{2}{*}{ IV } & 6 & Low & IVA & 8 \\
\hline & & High & IVB & 5 \\
\hline
\end{tabular}

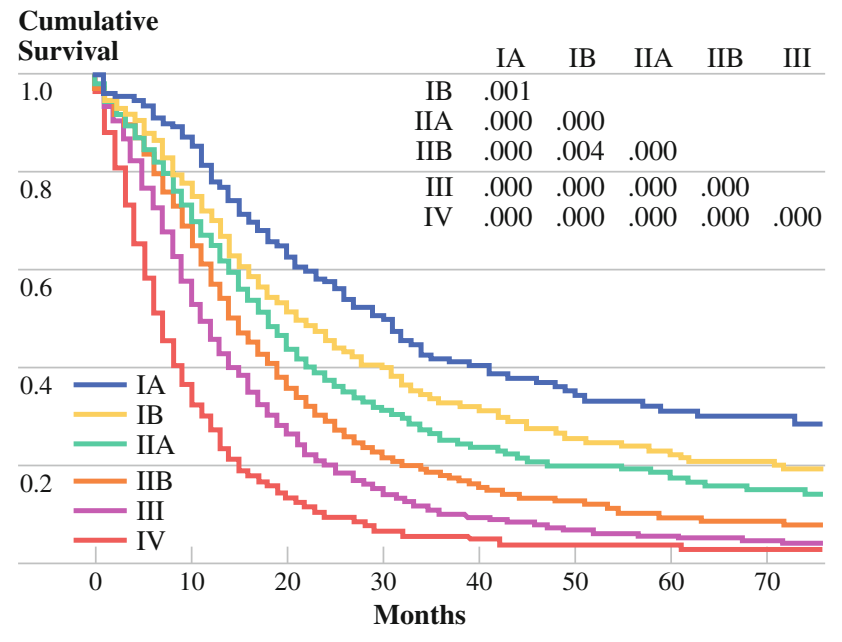

FIG. 2 Kaplan-Meier survival curves based on TNMG classification showing excellent discrimination between stages

regimen. ${ }^{26}$ In none of these trials were patients stratified by grade. Given the magnitude of difference in median survival in these adjuvant trials and the potential impact of grade on survival, it is feasible that stratifying upon grade could alter the median survival difference and possibly the significance of these trial results. We have shown that stratifying AJCC stage IIB resected tumors (node positive) by grade demonstrates a 4-month improvement in median survival for node-positive, low-grade tumors compared with node-positive, high-grade tumors, which is comparable to the difference in median survival seen in the trial results quoted previously. Some may argue that randomization would automatically adjust for this factor; however, given the degree to which most trials in pancreatic cancer are underpowered, the risk for bias resulting from inaccurate stratification becomes much greater with such an influential factor such as grade. This study shows that high tumor grade (HR 1.40) has a larger impact on survival than both node positivity (HR 1.38) and tumor size $>2 \mathrm{~cm}$ (HR 1.37), both of which are part of the current AJCC staging system and are used to risk stratify patients routinely.

Our data make a strong case for inclusion of tumor grade into current staging for pancreatic cancer; therefore, we proposed a novel TNMG staging system. With the addition of grade to the current AJCC staging system, we are better able to tease out the "best case scenario" patients in stage IA (low-grade tumors, $<2 \mathrm{~cm}$, node negative and localized to the pancreas) and show an improvement in median survival of 3 months compared with stage IA in TNM staging $(<2 \mathrm{~cm}$, node negative and localized). We can also identify the "bad actors" in stage IIA (high-grade tumors, node negative, and locally invasive) and move them to stage IIB in TNMG staging; again an improvement in median survival of 2 months compared with stage IIA in TNM staging. Furthermore, dividing stage IV patients into stage IVA (low grade with median survival 8 months) and stage IVB (high grade with median survival 5 months) provides better risk stratification in the very patient population most likely to enroll in future clinical trials to evaluate potential new therapies. Moreover, in support of our contention that discrimination in survival is improved with TNMG staging, the overall "spread" in median survival for TNMG staging is 25 months (range 5-30 months), which compares with 21 months with TNM staging (range 6-27 months). 
Importantly, we demonstrate that not only does addition of tumor grade makes sense given its significant and independent impact on survival, but it can be added to the existing TNM staging system in a relatively simple manner. In other words, the novel TNMG staging system proposed does not create a more complex staging system but rather builds upon the existing AJCC staging system with improved reflection of the underlying biology and associated impact on survival. This is not a trivial point as more complex staging systems such as the previously mentioned nomograms have not been widely adopted in spite of improved prognostication.

Tumor grade is already part of staging for prostate cancer, sarcomas, and certain bone tumors. For a prognostic factor to be included in the staging system, it must explain some of the heterogeneity associated with the expected course and outcome of a disease. ${ }^{1}$ Our analysis shows that tumor grade in pancreatic cancer meets this criterion. Pathology studies of pancreatic cancer have examined a scoring system based on grade, similar to Gleason score for prostate cancer, and have shown good predictive ability as well as reproducibility. ${ }^{27}$ Similarly Eltoum et al. devised a cytologic grading system for biopsy specimens obtained by endoscopic ultrasound-guided fineneedle aspiration to predict survival in patients with pancreatic adenocarcinoma. $^{28}$

The use of population-based data has several inherent limitations. Even though the database is checked regularly for discrepancy and reportedly has $95 \%$ accuracy, the possibility of coding errors remains. Furthermore, we cannot account for variability among SEER regions in pathology protocols used to assess tumor grade, as well as interobserver variability among pathologists. As mentioned previously, no information on chemotherapy is provided in the database so we were unable to assess the impact of adjuvant therapy. Additionally, margin status is not recorded in SEER. Nevertheless, the use of a population database enables us to study a large contemporary sample of patients and make significant statistical conclusions relevant to the general population, which is not possible in single-institution studies.

In this study we use the SEER cancer registry to show that tumor grade is a significant and independent prognostic factor for survival after resection of pancreatic adenocarcinoma. In fact, high tumor grade has a greater impact on survival in pancreatic cancer than known poor prognostic factors such as lymph node positivity and tumor size, which form the basis of our current staging system. We believe inclusion of tumor grade into AJCC staging for pancreatic cancer would enhance the current system and provide better survival prognostication reflective of the aggressive biology associated with high-grade tumors. These findings may have implications for adjuvant therapy decision making as well as risk stratification of patients entering future clinical trials.

ACKNOWLEDGMENT Supported by grants from the Gonda (Goldschmied) Research Laboratories of the John Wayne Cancer Institute at Saint John's Health Center. Supported by funding from QVC and the Fashion Footwear Association of New York Charitable Foundation (New York, NY), the Margie and Robert E. Petersen Foundation (Los Angeles, CA), Mrs. Lois Rosen (Los Angeles, CA), and the Associates for Breast and Prostate Cancer Studies (Santa Monica, CA). Supported by funding from the Family of Robert Novick (Los Angeles, CA), Ruth and Martin H. Weil Fund (Los Angeles, CA), and the Wrather Family Foundation (Los Alamos, CA).

OPEN ACCESS This article is distributed under the terms of the Creative Commons Attribution Noncommercial License which permits any noncommercial use, distribution, and reproduction in any medium, provided the original author(s) and source are credited.

\section{REFERENCES}

1. Greene FL, Sobin LH. The staging of cancer: a retrospective and prospective appraisal. CA Cancer J Clin. 2008;58:180-90.

2. Greene FL, Page DL, Fleming ID, Fritz A, Balch CM, Haller DG, et al., editors. American joint committee on cancer: AJCC cancer staging manual. 6th ed. New York, NY: Springer; 2002.

3. Bilimoria KY, Bentrem DJ, Ko CY, Ritchey J, Stewart AK, Winchester DP, et al. Validation of the 6th edition AJCC Pancreatic Cancer Staging System: report from the National Cancer Database. Cancer. 2007;110:738-44.

4. Brennan MF, Kattan MW, Klimstra D, Conlon K. Prognostic nomogram for patients undergoing resection for adenocarcinoma of the pancreas. Ann Surg. 2004;240:293-8.

5. Ferrone CR, Kattan MW, Tomlinson JS, Thayer SP, Brennan MF, Warshaw AL. Validation of a postresection pancreatic adenocarcinoma nomogram for disease-specific survival. J Clin Oncol. 2005;23:7529-35.

6. Geer RJ, Brennan MF. Prognostic indicators for survival after resection of pancreatic adenocarcinoma. Am J Surg. 1993;165: 68-72.

7. Lim JE, Chien MW, Earle CC. Prognostic factors following curative resection for pancreatic adenocarcinoma: a populationbased, linked database analysis of 396 patients. Ann Surg. 2003;237:74-85.

8. Winter JM, Cameron JL, Campbell KA, Arnold MA, Chang DC, Coleman J, et al. 1423 pancreaticoduodenectomies for pancreatic cancer: A single-institution experience. J Gastrointest Surg. 2006;10:1199-210.

9. Benassai G, Mastrorilli M, Quarto G, Cappiello A, Giani U, Forestieri $\mathrm{P}$, et al. Factors influencing survival after resection for ductal adenocarcinoma of the head of the pancreas. J Surg Oncol. 2000;73:212-8.

10. Gebhardt C, Meyer W, Reichel M, Wünsch PH. Prognostic factors in the operative treatment of ductal pancreatic carcinoma. Langenbecks Arch Surg. 2000;385:14-20.

11. Kuhlmann KF, de Castro SM, Wesseling JG, ten Kate FJ, Offerhaus GJ, Busch OR, et al. Surgical treatment of pancreatic adenocarcinoma; actual survival and prognostic factors in 343 patients. Eur J Cancer. 2004;40:549-58.

12. Kumar V, Fausto N, Abbas A. Robbins and Cotran pathologic basis of disease. 7th ed. Philadelphia: Saunders; 2004.

13. Havener L. Standards for cancer registries volume III: standards for completeness, quality, analysis, and management of data. 
Springfield, IL: North American Association of Central Cancer Registries; 2004.

14. Surveillance, Epidemiology, and End Results (SEER) Program. Public use data (1973-2005). National Cancer Institute. http:// www.seer.cancer.gov. Accessed October 2008.

15. Schwarz RE, Smith DD. Extent of lymph node retrieval and pancreatic cancer survival: information from a large US population database. Ann Surg Oncol. 2006;13:1189-200.

16. Tomlinson JS, Jain S, Bentrem DJ, Sekeris EG, Maggard MA, Hines OJ, et al. Accuracy of staging node-negative pancreas cancer: a potential quality measure. Arch Surg. 2007;142:767-73.

17. Takai S, Satoi S, Toyokawa H, Yanagimoto H, Sugimoto N, Tsuji $\mathrm{K}$, et al. Clinicopathologic evaluation after resection for ductal adenocarcinoma of the pancreas: a retrospective, single-institution experience. Pancreas. 2003;26:243-9.

18. Sperti C, Pasquali C, Piccoli A, Pedrazzoli S. Survival after resection for ductal adenocarcinoma of the pancreas. $\mathrm{Br} J$ Surg. 1996;83:625-31.

19. Kedra B, Popiela T, Sierzega M, Precht A. Prognostic factors of long-term survival after resective procedures for pancreatic cancer. Hepatogastroenterology. 2001;48:1762-6.

20. Nitecki SS, Sarr MG, Colby TV, van Heerden JA. Long-term survival after resection for ductal adenocarcinoma of the pancreas. Is it really improving? Ann Surg. 1995;221:59-66.

21. Raut CP, Tseng JF, Sun CC, Wang H, Wolff RA, Crane CH, et al. Impact of resection status on pattern of failure and survival after pancreaticoduodenectomy for pancreatic adenocarcinoma. Ann Surg. 2007;246:52-60.
22. Lightner AM, Glasgow RE, Jordan TH, Krassner AD, Way LW, Mulvihill SJ, et al. Pancreatic resection in the elderly. J Am Coll Surg. 2004;198:697-706.

23. Finlayson E, Fan Z, Birkmeyer JD. Outcomes in octogenarians undergoing high-risk cancer operation: a national study. $J \mathrm{Am}$ Coll Surg. 2007;205:729-34.

24. Oettle H, Post S, Neuhaus P, Gellert K, Langrehr J, Ridwelski K, et al. Adjuvant chemotherapy with gemcitabine vs. observation in patients undergoing curative-intent resection of pancreatic cancer: a randomized controlled trial. JAMA. 2007;297:267-77.

25. Neoptolemos JP, Stocken DD, Friess H, Bassi C, Dunn JA, Hickey H, et al. European Study Group for Pancreatic Cancer. A randomized trial of chemoradiotherapy and chemotherapy after resection of pancreatic cancer. $N$ Engl J Med. 2004;350:1200-10.

26. Picozzi VJ, Pisters PW, Vickers SM, Strasberg SM. Strength of the evidence: adjuvant therapy for resected pancreatic cancer. $J$ Gastrointest Surg. 2008;12:657-61.

27. Adsay NV, Basturk O, Bonnett M, Kilinc N, Andea AA, Feng J, et al. A proposal for a new and more practical grading scheme for pancreatic ductal adenocarcinoma. Am J Surg Pathol. 2005;29:724-33.

28. Eltoum IA, Eloubeidi MA, Chhieng DC, Tamhane A, Crowe R, Jhala $\mathrm{D}$, et al. Cytologic grade independently predicts survival of patients with pancreatic adenocarcinoma. Am J Clin Pathol. 2005;124:697-707. 